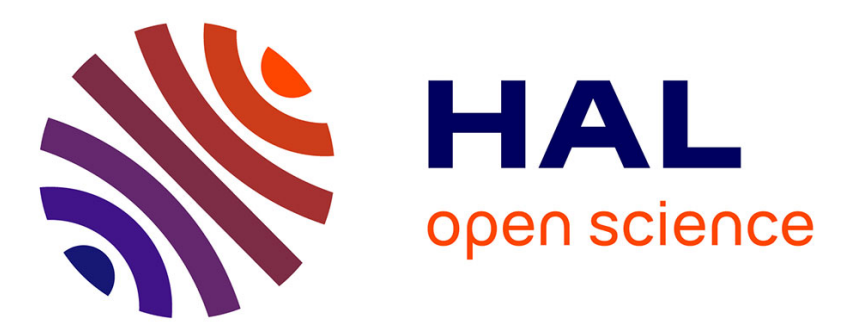

\title{
Characterization of potential TRPP2 regulating proteins in early Xenopus embryos
}

\author{
Mélinée Futel, Ronan Le Bouffant, Isabelle Buisson, Muriel Umbhauer, \\ Jean-Francois Riou
}

\section{- To cite this version:}

Mélinée Futel, Ronan Le Bouffant, Isabelle Buisson, Muriel Umbhauer, Jean-Francois Riou. Characterization of potential TRPP2 regulating proteins in early Xenopus embryos. Journal of Cellular Biochemistry, 2018, 119 (12), pp.10338-10350. 10.1002/jcb.27376 . hal-01981052

\section{HAL Id: hal-01981052 https://hal.sorbonne-universite.fr/hal-01981052}

Submitted on 14 Jan 2019

HAL is a multi-disciplinary open access archive for the deposit and dissemination of scientific research documents, whether they are published or not. The documents may come from teaching and research institutions in France or abroad, or from public or private research centers.
L'archive ouverte pluridisciplinaire HAL, est destinée au dépôt et à la diffusion de documents scientifiques de niveau recherche, publiés ou non, émanant des établissements d'enseignement et de recherche français ou étrangers, des laboratoires publics ou privés. 


\section{CHARACTERIZATION OF POTENTIAL TRPP2 REGULATING PROTEINS IN EARLY XENOPUS EMBRYOS}

Mélinée Futel ${ }^{1 *}$, Ronan Le Bouffant ${ }^{1 *}$, Isabelle Buisson ${ }^{1}$, Muriel Umbhauer $^{1}$ and Jean-François Riou ${ }^{1}$

${ }^{1}$ Sorbonne Université, CNRS, Institut de Biologie Paris-Seine, IBPS, Laboratoire de Biologie du Développement, UMR7622, 9, quai Saint-Bernard, 75252 Paris cedex05, France.

* Each author contributed equally to this work

Corresponding author: Jean-François Riou, Laboratoire de biologie du Développement-UMR7622, Institut de Biologie Paris-Seine, 9, quai Saint-Bernard, case 24, 75252 Paris cedex05, France Tel: 33144272773

Fx: 33144273445

Running head: TRPP2-interacting proteins in Xenopus embryo

Keywords: TRPP2, Xenopus embryo, primary cilium, pronephric field, dvl2, golgin A2, PrKD1

Total number of text figures and tables: 6 figures, 1 table, 2 supplemental tables

Grant information CNRS and UPMC funding of "Signaling and Morphogenesis team. 2010-2013 "Contrat Doctoral" from the doctoral school "Complexité du Vivant" for MF. 


\begin{abstract}
TRPP2 is a non-specific $\mathrm{Ca}^{++}$-dependent cation channel with versatile functions including control of extracellular calcium entry at the plasma membrane, release of intracellular calcium from internal stores of endoplasmic reticulum, and calcium-dependent mechanosensation in the primary cilium. In early Xenopus embryos, TRPP2 is expressed in cilia of the gastrocoel roof plate (GRP) involved in the establishment of left-right asymmetry, and in non-ciliated kidney field (KF) cells, where it plays a central role in early specification of nephron tubule cells dependent on intracellular calcium signaling. Identification of proteins binding to TRPP2 in embryo cells can provide interesting clues about the mechanisms involved in its regulation during these various processes. Using mass spectrometry (MS), we have therefore characterized proteins from late gastrula/early neurula stage embryos coimmunoprecipitating with TRPP2. Binding of three of these proteins, golgin A2, protein kinase-D1 and disheveled-2 has been confirmed by immunoblotting analysis of TRPP2-co-precipitated proteins. Expression analysis of the genes respectively encoding these proteins, golga2, prkd1 and $d v / 2$ indicates that they are likely to play a role in these two regions. Golga2 and prkd1 are expressed at later stage in the developing pronephric tubule where golgin A2 and protein kinase-D1 might also interact with TRPP2. Co-localization experiments using exogenously expressed fluorescent versions of TRPP2 and dv/2 in GRP and KF reveal that these two proteins are generally not co-expressed, and only co-localized in discrete region of cells. This was observed in KF cells, but does not appear to occur in the apical ciliated region of GRP cells.
\end{abstract}




\section{INTRODUCTION}

Transient receptor potential cation channel (TRPP)-2 also known as polycystin-2 is a non-specific $\mathrm{Ca}^{++}$-dependent cation channel. TRPP2 is encoded by the gene $p k d 2$. It can function as a channel regulating entry of extracellular $\mathrm{Ca}^{++}$at the plasma membrane, or release of internal $\mathrm{Ca}^{++}$stores from the endoplasmic reticulum (ER) [Kottgen, 2007]. Yet, the most studied function of TRPP2 concerns its role in the primary cilia. Several PKD2 mutations affecting the ciliary function of TRPP2 are responsible for autosomal dominant kidney disease (ADPKD) in humans [Ferreira et al., 2015]. TRPP2 can associate with polycystin-1 to form a complex that is thought to act as a mechanosensor upon cilium bending resulting from fluid flow in renal tubules [Paul and Vanden Heuvel, 2014]. Interfering with $p k d 2$ function causes formation of cysts in developing mouse kidney [Wu et al., 2000] and zebrafish pronephros [Sun et al., 2004], and dilated pronephric tubules in Xenopus [Tran et al., 2010]. In addition to its function in kidney tubule cells, TRPP2 plays an important role in the establishment of left-right asymmetry in vertebrate embryos, as shown by the laterality defects observed upon $p k d 2$ loss of function in mouse [Pennekamp et al., 2002] and zebrafish [Bisgrove et al., 2005]. Laterality defects in mouse $p k d 2$ mutants, have been related to the asymmetric generation of intracellular calcium $\left(\left[\mathrm{Ca}^{++}\right]_{i}\right)$ signaling on the left side of the node [McGrath et al., 2003].

In neurula stage Xenopus embryos, TRPP2 is expressed in cilia of the gastrocoel roof plate (GRP) [Schweickert et al., 2007], which is involved in the establishment of left-right asymmetry, and in nonciliated kidney field (KF) cells, where it plays a central role in $\left[\mathrm{Ca}^{++}\right]_{i}$ signaling. $\mathrm{KF}$, also called pronephric field is a region of dorso-lateral mesoderm containing specified kidney precursors that will take part to the development of the pronephros at later stages [Carroll and Vize, 1999]. Several genes including pax8, Ihx1, osr 1 and osr 2 are expressed in $\mathrm{KF}$, and play a major role in the specification of kidney precursors, as evidenced by their respective loss of function, all of which cause severe defects of pronephric development [Buisson et al., 2015; Chan et al., 2000; Tena et al., 2007]. $\mathrm{Ca}^{++}$transients are accumulated in a discrete region of the KF that eventually forms the pronephric tubule. Interfering with $\left[\mathrm{Ca}^{++}\right]_{\mathrm{i}}$ signaling with inducible $\mathrm{Ca}^{++}$chelators results in a downregulation of pax8 in the KF, and defective tubulogenesis at later stages [Futel et al., 2015; Leclerc et al., 2008]. Pkd2 knockdown results in a severe inhibition of $\mathrm{Ca}^{++}$transients in the $\mathrm{KF}$, and a dramatic down regulation of pax8, indicating that TRPP2 is playing a central role in this process [Futel et al., 2015]. KF specification is dependent on retinoic acid (RA) signals [Cartry et al., 2006], and might also involve Wnt11b [Tetelin and Jones, 2010]. Although Wnt11b could potentially cause $\mathrm{Ca}^{++}$release in the cytosol through the activation of the Wnt-calcium pathway, and Wnts have been recently shown 
to activate polycystin-1/TRPP2 complex channel activity [Kim et al., 2016], the potential role of Wnt11b in this process has not been studied. In contrast, we have shown that both $\left[\mathrm{Ca}^{++}\right]_{\mathrm{i}}$ signaling and TRPP2 expression at the plasma membrane in KF cells are severely impaired upon disruption of RA signaling, pointing to RA-dependent control of TRPP2 trafficking to the plasma membrane as an important regulatory mechanisms of $\left[\mathrm{Ca}^{++}\right]_{i}$ signaling in the KF [Futel et al., 2015].

Because of the versatile functions played by TRPP2, several mechanisms involved in the modulation of TRPP2 function have been described, including association with other TRP proteins to form heteromeric channels [Giamarchi et al., 2010; Kottgen et al., 2008], TRPP2 phosphorylation [Cai et al., 2004; Streets et al., 2010] and/or regulation of intracellular trafficking [Hoffmeister et al., 2011; Kottgen et al., 2005], and potential interaction with Wnt-calcium signaling pathway [Kim et al., 2016]. Although TRPP2 has been previously shown to be involved in the establishment of left-right asymmetry, as well as in the formation of KF, how TRPP2 function(s) can be controlled in the early embryo is largely ignored. Identification of proteins binding to TRPP2 can provide important information about potential TRPP2 modulatory mechanisms taking place in early Xenopus embryos, during processes involving a ciliary function of TRPP2, such as those occurring in the GRP, or where TRPP2 is thought to act at the plasma membrane, as in KF cells. In addition, Xenopus developing pronephros is widely used as a model for vertebrate nephrogenesis, and has allowed to obtain important data concerning mir17/bicaudal C control of $p k d 2$ expression [Tran et al., 2010], or polycystin-1-dependent TRPP2 phosphorylation processes [Streets et al., 2013], that have proved to be important in the study of mammalian nephrogenesis and ADPKD [Lienkamp, 2016]. We have therefore undertaken a characterization of proteins interacting with TRPP2 in late gastrula/early neurula stage embryos, using mass spectrometry (MS) analysis of proteins co-immunoprecipitated with TRPP2.

\section{MATERIALS AND METHODS}

\section{EMBRYOS}

Xenopus embryos have been obtained as previously described by human chorionic gonadotropin stimulation of females and in vitro fertilization [Futel et al., 2015], and staged according to [Nieuwkoop and Faber, 1975]. All animal experiments were carried out according to approved guidelines validated by the Ethics Committee on Animal Experiments "Charles Darwin"(C2EA-05) with the "Autorisation de projet" number 02164.02.

IMMUNOPRECIPITATION 
Embryo protein extraction has been performed as previously reported [Le Bouffant et al., 2012], in extraction buffer (100mM NaCl, 5mM EDTA, 0.5\% NP40,10mM Tris pH 7.5) containing phosphatases and proteases inhibitor cocktails (cOmplete ULTRA, PhosSTOP, Roche). For immunoprecipitation, embryo lysates were incubated during $2 \mathrm{~h}$ at $4^{\circ} \mathrm{C}$ with anti-rabbit lg coated Dynabeads (Dynabeads $\mathrm{M}$ 280 , Thermo Fisher) previously coupled with the antibody of interest according to manufacturer's instructions. Prior to incubation with lysates, antibodies complexes were crosslinked using $20 \mathrm{mM}$ dimethyl pimelimidate according to manufacturer instructions. Crosslinking was not performed when immunoprecipitates were used for MS analysis because they were not eluted, and were directly digested on beads (see below). Beads were washed once with extraction buffer followed by 3 washes with $500 \mathrm{mM} \mathrm{NaCl}, 50 \mathrm{mM}$ Tris pH7.5, 1\% NP40, and a final wash in phosphate-buffered saline (PBS) before elution of immunoprecipitated proteins in Laemmli sample buffer, or processing for MS analysis (see below).

Western immunoblotting analyses were carried out as previously described [Le Bouffant et al., 2012]. Primary antibodies included rabbit polyclonal anti-human TRPP2 (Novus Biochemicals \#NB10092215; 1/1000), anti-human Golgin A2 (Abcam \#ab103416; 1/2000), anti-human PrKD1 (Abcam \#ab131460, 1/2000), and anti-human dvl2 (Proteintech \#12037-1-AP; 1/1000) antibodies. Mouse monoclonal anti- $\alpha$-tubulin (Sigma T9026; 1:10,000) was used as loading control for input lysates. Secondary peroxidase-conjugated antibodies (goat-anti-rabbit or goat-anti-mouse IgG antisera; Jackson Laboratories) were used at 1:10,000.

\section{MS ANALYSIS}

Immunoprecipitated proteins were digested directly on beads overnight at $37^{\circ} \mathrm{C}$ by sequencing grade trypsin (12,5 $\mu \mathrm{g} / \mathrm{ml}$; Promega Madison, Wi, USA) in $20 \mu \mathrm{l}$ of $\mathrm{NH}_{4} \mathrm{HCO}_{3} 25 \mathrm{mmol} / \mathrm{L}$. Peptides were analyzed by an Easy nano-LC Proxeon system (Thermo Fisher Scientific, San Jose, CA) coupled to a LTQ Velos Orbitrap mass spectrometer (Thermo Fisher Scientific, San Jose, CA). Chromatographic separation of peptides was performed with the following parameters: C18 Easy column Proxeon (2 $\mathrm{cm}$ long, $5 \mu \mathrm{m}$ particle size) for peptide pre-concentration, column Easy Column Proxeon C18 $(10 \mathrm{~cm}$, $75 \mu \mathrm{m}$ i.d., 120 A), 300nl/min flow, gradient rising from $95 \%$ solvent A (water - 0,1\% formic acid) to $25 \%$ B (100 \% acetonitrile, 0,1\% formic acid) in 20 minutes, then to $45 \%$ B in 40 min and finally to $80 \% \mathrm{~B}$ in $10 \mathrm{~min}$. Peptides were analyzed in the orbitrap in full ion scan mode with a mass resolution of 30000 (at $\mathrm{m} / \mathrm{z} 400$ ) over the range $\mathrm{m} / \mathrm{z}$ 400-1800. A collision-induced dissociation (CID) activation was used for peptide fragmentation with a collisional energy of $40 \%$, an activation $Q$ of 0,250 for 10 ms. MS/MS data were acquired in the LTQ in a data dependent mode in which 20 most intense precursor ions were isolated. Maximum allowed ion accumulation times were set to $100 \mathrm{~ms}$ for MS 
and $50 \mathrm{~ms}$ for MS/MS scans. Data were analyzed using Proteome Discoverer 1.3 software (Thermo Fisher scientific, San Jose, CA) coupled to an in house Mascot search server (Matrix Science, Boston, $M A$; version 2.3.2). The mass tolerance of fragment ions was set to $10 \mathrm{ppm}$ for precursor ions and 0.6 Da for fragments. Oxidation (M) and phosphorylations (STY) were chosen as variable modifications. The maximum number of missed cleavages was limited to 2 for trypsin digestion. Raw files were searched against NCBInr database with the Xenopus laevis taxonomy. A Decoy database approach was used for the False Discovery Rate (FDR) estimation. The target FDR was set to $1 \%$. The Mascot scores were calculated as follows: $-10 \log (\mathrm{P})$ where $\mathrm{P}$ is the absolute probability that the event is not random.

\section{ANALYSES OF GENE EXPRESSION}

Whole mounted in situ hybridization has been carried out as described [Colas et al., 2008]. Embryos were fixed in MEMFA (3.7\% formaline in 2mM EGTA, $1 \mathrm{mM} \mathrm{MgSO}_{4}, 0.1 \mathrm{M} \mathrm{MOPS} \mathrm{pH} \mathrm{7.4),} \mathrm{hybridized}$ with digoxygenin-labelled riboprobes, and bound probes further detected with phosphataseconjugated sheep anti-digoxygenin antibodies according to the method of [Harland, 1991]. Chromogenic reaction with alkaline phophatase was done with BM purple reagent (Roche). DNA sequences used to transcribe antisense riboprobes for golga 2 and prkd1 were cloned by PCR amplification using the following primers: golga2 5'-CACTGAGCCCACACCACCT-3' forward, 5'TGACTGGACTTCCCGTCTCC-3' reverse, and prkd1 5'-CCATCGTGGACCAAAAGTTTC-3' forward, 5'CCAAACTGGCCTGATCCAAG-3' reverse. They were further subcloned into pCRII vectors (InVitrogen) for antisense probe synthesis.

Real time quantitative PCR (RT-qPCR) has been performed as previously reported [Le Bouffant et al., 2012]. The Comparative $\mathrm{Ct}$ method was used to determine the relative quantities of mRNA, using ornithine decarboxylase (odc) mRNA as the endogenous reporter. Each RNA sample was analyzed in duplicate. Each data point represents the mean \pm SEM of at least three independent experiments. Data were analyzed using R Commander (R software) by paired Student's t-test. Primers used for RTqPCR are given in supplemental table 1.

\section{MICROINJECTION OF MRNA AND ANALYSIS OF FLUORESCENT PROTEINS LOCALIZATION}

Synthesis of capped mRNA and microinjection has been carried out as described [Colas et al., 2008]. A plasmid encoding Xenopus dvl2-mcherry (pCS2+-dvl2-mcherry) was obtained by replacing the GFP sequence of pCS2+-dvl2-GFP [Gentzel et al., 2015] by that of mcherry. Plasmids encoding human GFP-TRPP2 (pCS2+-GFP-hPKD2) [Hoffmeister et al., 2011] and arl13b-mcherry (pCS2+-arl13bmcherry) [Borovina et al., 2010] have been previously described [Futel et al., 2015]. All plasmids were 
linearized with asp718 and transcribed with SP6 RNA polymerase. GRP and KF explant dissection procedures have been previously described [Futel et al., 2015; Schweickert et al., 2007]. Dissected explants were immediately transferred into ice-cold $4 \%$ paraformaldehyde and fixed overnight at $4{ }^{\circ} \mathrm{C}$. After two washes in PBS, explants were mounted as whole-mounts into Mowiol 4-88. Observations were performed on a Zeiss Z1 inverted microscope equipped with ApoTome optical sectioning device. Monochrome images were analyzed using imageJ software. Artificially colorized images and merge images were obtained using Adobe Photoshop CS4.

\section{RESULTS}

\section{IDENTIFICATION OF GOLGIN A2, PROTEINE KINASE-D1 AND DISHEVELED-2 AS PROTEINS} INTERACTING WITH TRPP2 IN EARLY NEURULA EMBRYOS

In an attempt to identify proteins potentially modulating TRPP2 function in Xenopus neurulae, we have analyzed proteins binding to immunoprecipitated TRPP2 using MS. The analysis was performed at late gastrula-early neurula stage (NFst.12.5-13) from whole embryo extracts. Proteins immunoprecipitated by the anti-TRPP2 antibody from NFst.12.5-13 embryo extracts have been subjected to MS analysis (Fig1A). Comparison of anti-TRPP2 immunoprecipitates (IPs) and control IPs without primary antibody allowed the identification of 62 proteins specifically detected in TRPP2 IPS and absent from control IPs (table S2). We focused on proteins potentially involved in trafficking, interaction with Wnt-calcium pathway or cilia function (table 1).

Highest Mascot scores were observed for golgin A2 (also known as GM130), protein kinase-D1 (PrKD1), also known as PKC- $\mu$ ) and disheveled-2 (dvl2) (table 1). These three proteins can potentially play a modulatory role of TRPP2 function in Xenopus embryo cells. Golgin A2 is a component of the cis-Golgi matrix [Nakamura et al., 1995] involved in TRPP2 trafficking [Hidaka et al., 2004; Hoffmeister et al., 2011]. PrKD1-dependent phosphorylation of TRPP2 Ser801 has been shown to play an important role in the modulation of $\mathrm{Ca}^{2+}$ release from ER stores in a non-ciliated MDCK cell line [Streets et al., 2010]. Dvl2 has been recently shown to physically interact with polycystin-1 in mouse embryo fibroblasts, where it can form a complex with TRPP2 through TRPP2 interaction with polycystin-1 [Kim et al., 2016].

Interactions between TRPP2 and golgin A2, PrKD1 or dvl2 were confirmed by co-IP experiments carried out with early neurula stage protein extracts. Western immunoblotting analysis of proteins associated with TRPP2 after TRPP2 immunoprecipitation showed that golgin A2, PrKD1 and dv12 were all detected in Anti-TRPP2 IPs (Fig.1B). Interactions between PrKD1 and TRPP2, as well as between GolginA2 and TRPP2, were respectively confirmed by anti-PrKD1 and anti-golgin A2 IPs (Fig.1C), but 
we were unable to detect TRPP2 in anti-dvl2 IPs (data not shown). It is possible that only a small proportion of total dvl2 is bound to TRPP2, making the amount of TRPP2 co-immunoprecipitated with dv12 difficult to detect by immunoblotting. Although TRPP2 could be detected both in IPs of anti-Golgin A2 and anti-PrKD1, neither PrKD1 was detected in anti-golgin A2 IPs, nor Golgin A2 in anti-PrKD1 IPs (Fig.1C). This indicates that these three proteins are not forming a single complex.

\section{Golga2, prkd1 AND $d v / 2$ GENES ARE EXPRESSED IN KF AND GRP REGIONS OF THE NEURULA EMBRYOS}

In an attempt to evaluate whether TRPP2-interacting proteins detected in whole neurula embryos can potentially play a role in GRP or $\mathrm{KF}$, we have analyzed whether their respective encoding genes golga2, prkd1 and $d v / 2$ are expressed in these tissues. GRP or KF explants were dissected from early neurula stage embryos (Fig.2A) and their transcript content was subjected to RT-qPCR analysis for golga2, prkd1 and dv/2 expression, using odc expression for normalization. Enrichment of GRP or KF tissue was assessed in parallel by analyzing expression of brachyury $(t)$ in GRP samples or pax8 in KF samples (Fig.2B). Brachyury $(t)$ is highly expressed in tailbud and caudal notochord at neurula stage [Gont et al., 1993]. These structures are close to the caudal neural plate where sits the GRP [Schweickert et al., 2007]. Pax8 is highly expressed in KF cells [Carroll and Vize, 1999]. Results are shown in Fig.2B. As expected, brachyury $(t)$ is highly enriched in GRP samples, while it is only detected at very low levels in KF samples. Conversely, pax8 is strongly expressed in KF samples but is undetectable in GRP samples. Analysis of golga2, prkd1 and $d v / 2$ expression does not reveal any preferential expression in GRP or KF. All three genes expression are readily detected in both GRP and $\mathrm{KF}$, indicating that their respective encoded proteins are likely to play roles both in ciliated GRP cells, and in non-ciliated cells of the KF.

\section{Prkd1 AND golga2 ARE EXPRESSED THROUGHOUT DEVELOPMENT WITH HIGH LEVELS OF EXPRESSION IN THE DEVELOPING KIDNEY.}

We further investigated how golga2, and prkd1 are expressed during Xenopus development. We paid particular attention to the developing pronephros, since it has already been used to study different aspects of $p k d 2$ function during vertebrate nephrogenesis that can be impaired in ADPKD [Lienkamp, 2016; Streets et al., 2013; Tran et al., 2010]. Dv/2 expression during Xenopus development has been studied previously [Gray et al., 2009] and is part of genes of the wnt signaling pathway expressed in the developing pronephros [Zhang et al., 2011]. Our own observations totally confirm these expression patterns, especially the pronephric expression of $d v / 2$ (data not shown).

Temporal expression was investigated by RT-qPCR. Both genes are expressed at all the stages investigated, ranging from 16-cell stage (NFst.5), when gene expression only relies on maternal 
transcripts, to later cleavage stages, gastrulation, neurulation, and tailbud stages until pronephros starts to be functional (NFst.37). Golga2 and prkd1 appear to have a very strong maternal expression. Expression is high until mid-gastrula stage (NFst.11), and then progressively drops (Fig.3).

Spatial expression was further investigated using whole-mount in situ hybridization. During gastrulation, both golga2 and prkd1 appear to be expressed in all tissues. However, there is higher expression in the marginal zone at early gastrula stage (NFst.10), especially on the dorsal side. At late gastrula stage (NFst.12.5), expression of golga2 is observed in the entire embryo, but is clearly stronger in axial mesoderm. Likewise, prkd1 transcripts are detected throughout the late gastrula embryo with a slightly higher expression on the dorsal side of the closing blastopore (Fig.4A). At tailbud stages, golga 2 and prkd1 are strongly expressed in the developing brain and developing eyes. They are detected in migrating cranial neural crest at early tailbud stage (NFst.24), and later in the developing branchial arches. Golga2 is expressed in mesoderm in the developing notochord. It is clearly expressed in the pronephric anlage at early tailbud stage. Its expression is maintained at mid and late tailbud stages (NFst.29/30 and 33/34) in the proximal region of the pronephric tubule. Prkd1 transcripts are also detected in the developing notochord and pronephros. However, prkd1 is expressed in intermediate and distal segments of the developing pronephric tubule (Fig.4B).

\section{TRPP2 AND DVL2 CO-LOCALIZATION IS RESTRICTED TO DISCRETE REGIONS OF CELL BORDERS}

In a further attempt to localize where TRPP2 and dvl2 can interact in potential wnt-dependent processes, we have expressed fluorescent versions of these proteins in GRP and KF regions of neurula stage embryos, and observed their distribution in whole-mounted explants. These fluorescent versions of TRPP2 and dvl2 have been previously used to visualize TRPP2 and dvl2 expression in living cells [Hoffmeister et al., 2011; Gentzel et al., 2015]. In GRP explants, we focused on the ciliated apical region of GRP cells. In that case, localization of dvl2-GFP or TRPP2-GFP in the cilium was analyzed in cilia visualized using expression of arl13b-mcherry, as previously described [Futel et al., 2015]. Arl13b is a member of the small GTPases subfamily Arf/Arl localizing to primary cilium axoneme [Borovina et al., 2010].

Localization of dvl2-GFP in GRP cells was mostly restricted to the basis of the cilium revealed by the expression of arl13b-mcherry, and at the level of cell borders. In rare cases, we also observed dv/2GFP fluorescence in the cilium (Fig.5A-C). In contrast, GFP-TRPP2 co-localized with arl13b-mcherry in many cilia (Fig.5D-F). Expression of dvl2-mcherry with GFP-TRPP2 did not reveal dvl2 and TRPP2 colocalization in GRP cells cilia (Fig5G-I). Dvl2-mcherry was observed at the basis of cilia, as also observed with dvl2-GFP, but we failed to detect it in cilia expressing GFP-TRPP2. Dv12-mcherry was 
also clearly observed at cell borders, but GFP-TRPP2 was not. Although we cannot rule out that TRPP2 and dvl2 may interact in rare cilia where dvl2-GFP had been observed, our observations suggest that dvl2 interaction with TRPP2 is not significantly taking place in the ciliated apical region of GRP cells.

Co-localization between GFP-TRPP2 and dvl2-mcherry can be observed in KF explants, but only in some discrete regions. Optical sections through the most external part of KF cells rather showed an exclusion of GFP and mcherry fluorescence distribution (Fig.6A-C). As observed in GRP cells, dvl2mcherry fluorescence was associated with cell borders, while GFP-TRPP2 was not. GFP-TRPP2 was expressed in inner part of the cell as dots, possibly corresponding to traffic vesicle. Dvl2-mcherry was also detected as dots but distinct from GFP-TRPP2, indicating that interaction is not taking place in these structures (Fig.6A-C). Optical sections through deeper part of KF cells did not reveal a general co-localization of dv12-mcherry and GFP-TRPP2 (fig.6D-F). Still, co-localization could be observed in discrete regions of cell borders, as shown in Fig.6F. These observations show that interaction between TRPP2 and dvl2 is not a general feature. This raises the possibility that it might be only transient, and could be tightly regulated, as for example by signaling events. 


\section{DISCUSSION}

In order to provide more information about potential regulators of TRPP2 function(s) during early vertebrate development, it is necessary to establish a better correlation with proteins interacting with TRPP2 that might play an important role in the regulation of these different function(s). These data can be also of potential value for the understanding of the mechanisms underlying cyst formation during ADPKD in human. The early Xenopus embryo provides an interesting system where TRPP2 plays critical functions both in ciliated cells of the GRP, and in non-ciliated KF cells. We have therefore characterized proteins interacting with TRPP2 in late gastrula/early neurula stage embryos using MS analysis of proteins co-immunoprecipitated with TRPP2. Interaction has been confirmed by immunoblotting of immunoprecipitated proteins for three of them, golginA2, PrKD1 and dvl2. Expression analysis of the genes respectively encoding these proteins, golga2, prkd1 and $d v / 2$, indicates that they are likely to play a role in ciliated cells of the GRP involved in the establishment of left-right asymmetry, as well as in non-ciliated cells of the KF, both tissues where TRPP2 is thought to play important functions. At later stages, golga 2 and prkd1 are strongly expressed in the developing pronephros, as also previously reported for $d v / 2$ [Zhang et al., 2011], indicating that they might be also involved in later processes involving TRPP2. Further attempt to characterize dv12 and TRPP2 interactions, by analyzing dvl2 and TRPP2 co-localization in KF and GRP cells at neurula stage, reveals that interaction is only taking place in very discrete regions of cell borders, in line with the idea that dvI2-TRPP2 interactions might be related with dynamic features of Wnt signaling, rather than with the stable formation of a complex.

TRPP2 interaction with golgin-A2 is probably related with TRPP2 trafficking to the plasma membrane. Golgin family members are important for the specificity and efficiency of traffic at the level of the Golgi. Golgin A2 (GM130) is known to be involved in the tethering of transport vesicles, facilitating ER to Golgi traffic [Seemann et al., 2000; Wong and Munro, 2014]. Although dispensable during mouse development, global knock-out of GM130 causes a developmental delay, a global ataxia and a postnatal death. Its targeted deletion in the brain results in severe neurological defects. It strongly affects secretory trafficking and positioning of Golgi apparatus in Purkinje cells [Liu et al., 2017]. Knockdown of Golgin A2 (GM130) in human hTERT-RPE1 cells does not affect cilium formation [Asante et al., 2013], but this may result from redundancy between members of the golgin family. It has been indeed shown that Golgin A2 (GM130) and golgin GMAP-210 are acting redundantly in anterograde ER to golgi trafficking in HeLa cells [Roboti et al., 2015]. VPS15 whose mutation is causing ciliopathies, including nephropathies, has been recently shown to play a role in ciliogenesis 
or cilia function. It can form a complex with golgin A2 (GM130), and it has been proposed that this complex could be involved in IFT20-dependent trafficking to the cilium [Stoetzel et al., 2016]. Whether golgin A2 may play also a role in TRPP2 trafficking to the cilium remains unclear. Interaction of golgin A2 with TRPP2 has been previously described. It involves the interaction of the C-terminal tail of TRPP2 with a protein called PIGEA-14 identified in yeast two-hybrid screen (also called chibby1), which in turn binds to golgin A2. Co-expression of PIGEA-14 and TRPP2 in HeLa cells, as well as in porcine renal epithelial cells LLC-PK1, causes a redistribution of PIGEA-14 and TRPP2 to the transGolgi, suggesting that PIGEA-14 might be involved in the control of TRPP2 intracellular localization [Hidaka et al., 2004]. Although interaction with PIGEA-14 is dispensable for TRPP2 trafficking to cilia in LLC-PK ${ }_{1}$ cells [Hoffmeister et al., 2011], TRPP2 interaction with golgin A2 might be of importance in TRPP2 trafficking between ER and Golgi. The cby1 gene encoding chibby-1 in Xenopus is expressed throughout development [Shi et al., 2014], but we have not identified chibby-1 among proteins coprecipitated with TRPP2. Whether TRPP2 interacts with golgin A2 in Xenopus embryo cells by the mean of chibby-1, or whether this interaction involves a different mechanism still remains unclear.

Our results show that PrKD1 forms complexes with TRPP2 in Xenopus neurula cells. PrKD1 has been previously shown to be critical for TRPP2 function as an ER Ca ${ }^{2+}$-release channel in MDKC I cells. It phosphorylates $\mathrm{Ser}^{801}$ of human TRPP2. Mutation of $\mathrm{Ser}^{801}$ to glycine results in a loss of $\mathrm{Ca}^{2+}$-induced $\mathrm{Ca}^{2+}$ release mechanism [Streets et al., 2010]. This Ser residue is conserved in Xenopus TRPP2 $\left(\operatorname{Ser}^{779}\right)$, as well as the consensus recognition sequence of PrKD1 around Ser ${ }^{779}$ [Nishikawa et al., 1997], indicating that PrKD1 may modulate TRPP2 function in Xenopus embryo cells. Whether PrKD1 interacts with TRPP2 in the ER of Xenopus embryo cells needs further investigation. However, we observed that Golgin A2 IPs never contained PrKD1, nor PrKD1 IPs contained Golgin A2, although both contained TRPP2. This suggests that these complexes may correspond to different pools of TRPP2, and that PrKD1 is not expressed in the same compartment than golginA2 in Xenopus neurula cells. Our previous results indicate that RA-dependent trafficking of TRPP2 to the plasma membrane is critical for the production of calcium transients in KF cells [Futel et al., 2015], suggesting that these transients may be dependent on the entry of extracellular calcium, rather than on mobilization of internal stores. However, TRPP2 might have a potential additional role as an ER $\mathrm{Ca}^{2+}$-release channel in Xenopus embryo cells. It is remarkable, for instance, that TRPP2 has been shown to interact with the inositol 1,4,5-trisphosphate receptor (IP3R), and that these complexes are responsible for a TRPP2-dependent potentiation of IP3-induced $\mathrm{Ca}^{2+}$ release [Sammels et al., 2010], raising the possibility that TRPP2 may also play a role in embryonic cells by potentiating response to Wnt/calcium signaling pathways regulating IP3 [Saneyoshi et al., 2002]. 
Finally, our results show that dvl2 is forming a complex with TRPP2 in Xenopus embryo cells. Colocalization experiments further indicate that this interaction is not a general feature in GRP and KF cells. In GRP cilia, dv2 and TRPP2 rather appear to be expressed in contiguous parts, with dv/2 localized at the base of the cilium, while TRPP2 is rather expressed in the more distal part. It is unclear, however, whether co-localization in KF cells results from a transient interaction that could be dependent on wnt signaling. A truncated form of $d v 12$ has been used to interfere with tubule elongation at later stages of Xenopus pronephros development where it affects mediolateral cell intercalation in a similar manner to that observed in the developing Wnt9b-mutant mouse kidney, and might be related with congenital kidney cyst formation associated with defective Planar Cell Polarity (PCP) signaling [Lienkamp et al., 2012]. Interaction of dvl2 with polycystin-1 has been demonstrated in mouse embryo fibroblasts, and it is therefore possible that dvl2 can coimmunoprecipitate with TRPP2 in a complex made of TRPP2, polycystin-1 and dvl2 [Kim et al., 2016]. Interaction of TRPP2 and polycystin-1 has not been described in Xenopus embryos, but the pkd1 gene is expressed at late gastrula stage [Burtey et al., 2005]. TRPP2/dvl2 co-localization experiments in GRP and KF do not argue for a stable formation of TRPP2 and dvl2 complexes. TRPP2/polycystin-1 complexes have been shown to form a ligand-induced calcium channel activated by several wnts. Although dvl2 binding to the complex is dispensable for wnt-induced channel activity, it is possible that it is related to more complex aspects of wnt signaling dependent on local calcium release [Kim et al., 2016].

\section{ACKNOWLEDGEMENTS}

We thank S. Authier and E. Manzoni for excellent technical assistance in the maintenance of the Xenopus animal facility. We also would like to thank A. Schambony for information about anti-dvl2 antibody, and for providing dvl2-GFP expression plasmid. We are also extremely grateful to T. Léger at the core facility Proteomics of Institut J. Monod for help and advice with MS analysis. This work was supported by grants from CNRS and from Université Pierre et Marie Curie. MF was financed by a 2010-2013 "Contrat Doctoral" from the doctoral school "Complexité du Vivant".

\section{REFERENCES}

Asante D, Maccarthy-Morrogh L, Townley AK, Weiss MA, Katayama K, Palmer KJ, Suzuki H, Westlake CJ, Stephens DJ. 2013. A role for the Golgi matrix protein giantin in ciliogenesis through control of the localization of dynein-2. J Cell Sci 126:5189-97.

Bisgrove BW, Snarr BS, Emrazian A, Yost HJ. 2005. Polaris and Polycystin-2 in dorsal forerunner cells and Kupffer's vesicle are required for specification of the zebrafish left-right axis. Developmental Biology 287:274-288. 
Borovina A, Superina S, Voskas D, Ciruna B. 2010. Vangl2 directs the posterior tilting and asymmetric localization of motile primary cilia. Nature Cell Biology 12:407-U242.

Buisson I, Le Bouffant R, Futel M, Riou JF, Umbhauer M. 2015. Pax8 and Pax2 are specifically required at different steps of Xenopus pronephros development. Dev Biol 397:175-90.

Burtey S, Leclerc C, Nabais E, Munch P, Gohory C, Moreau M, Fontes M. 2005. Cloning and expression of the amphibian homologue of the human PKD1 gene. Gene 357:29-36.

Cai YQ, Anyatonwu G, Okuhara D, Lee KB, Yu ZH, Onoe T, Mei CL, Qian Q, Geng L, Wiztgall R, Ehrlich $\mathrm{BE}$, Somlo S. 2004. Calcium dependence of polycystin-2 channel activity is modulated by phosphorylation at Ser(812). Journal of Biological Chemistry 279:19987-19995.

Carroll TJ, Vize PD. 1999. Synergism between Pax-8 and lim-1 in embryonic kidney development. Dev Biol 214:46-59.

Cartry J, Nichane M, Ribes V, Colas A, Riou JF, Pieler T, Dolle P, Bellefroid EJ, Umbhauer M. 2006. Retinoic acid signalling is required for specification of pronephric cell fate. Dev Biol 299:35-51.

Chan TC, Takahashi S, Asashima M. 2000. A role for Xlim-1 in pronephros development in Xenopus laevis. Developmental Biology 228:256-269.

Colas A, Cartry J, Buisson I, Umbhauer M, Smith JC, Riou JF. 2008. Mix.1/2-dependent control of FGF availability during gastrulation is essential for pronephros development in Xenopus. Dev Biol 320:351-65.

Ferreira FM, Watanabe EH, Onuchic LF. 2015. Polycystins and Molecular Basis of Autosomal Dominant Polycystic Kidney Disease. In Li X, editor^editors. Polycystic Kidney Disease. Brisbane (AU).

Futel M, Leclerc C, Le Bouffant R, Buisson I, Neant I, Umbhauer M, Moreau M, Riou JF. 2015. TRPP2dependent $\mathrm{Ca} 2+$ signaling in dorso-lateral mesoderm is required for kidney field establishment in Xenopus. J Cell Sci 128:888-99.

Gentzel M, Schille C, Rauschenberger V, Schambony A. 2015. Distinct functionality of dishevelled isoforms on $\mathrm{Ca} 2+/$ calmodulin-dependent protein kinase 2 (CamKII) in Xenopus gastrulation. Molecular Biology of the Cell 26:966-977.

Giamarchi A, Feng S, Rodat-Despoix L, Xu Y, Bubenshchikova E, Newby LJ, Hao J, Gaudioso C, Crest M, Lupas AN, Honore E, Williamson MP, Obara T, Ong AC, Delmas P. 2010. A polycystin-2 (TRPP2) dimerization domain essential for the function of heteromeric polycystin complexes. EMBO J 29:1176-91.

Gont LK, Steinbeisser H, Blumberg B, Derobertis EM. 1993. Tail Formation as a Continuation of Gastrulation - the Multiple Cell-Populations of the Xenopus Tailbud Derive from the Late Blastopore Lip. Development 119:991-1004.

Gray RS, Bayly RD, Green SA, Agarwala S, Lowe CJ, Wallingford JB. 2009. Diversification of the Expression Patterns and Developmental Functions of the Dishevelled Gene Family During Chordate Evolution. Developmental Dynamics 238:2044-2057.

Harland RM. 1991. In situ hybridization: an improved whole-mount method for Xenopus embryos. Methods Cell Biol 36:685-95. 
Hidaka S, Konecke V, Osten L, Witzgall R. 2004. PIGEA-14, a novel coiled-coil protein affecting the intracellular distribution of polycystin-2. Journal of Biological Chemistry 279:35009-35016.

Hoffmeister H, Babinger K, Gurster S, Cedzich A, Meese C, Schadendorf K, Osten L, de Vries U, Rascle A, Witzgall R. 2011. Polycystin-2 takes different routes to the somatic and ciliary plasma membrane. Journal of Cell Biology 192:631-645.

Kim S, Nie HG, Nesin V, Tran U, Outeda P, Bai CX, Keeling J, Maskey D, Watnick T, Wessely O, Tsiokas L. 2016. The polycystin complex mediates Wnt/Ca2+ signalling. Nature Cell Biology 18:752-+.

Kottgen M. 2007. TRPP2 and autosomal dominant polycystic kidney disease. Biochimica Et Biophysica Acta-Molecular Basis of Disease 1772:836-850.

Kottgen M, Benzing T, Simmen T, Tauber R, Buchholz B, Feliciangeli S, Huber TB, Schermer B, KramerZucker A, Hopker K, Simmen KC, Tschucke CC, Sandford R, Kim E, Thomas G, Walz G. 2005. Trafficking of TRPP2 by PACS proteins represents a novel mechanism of ion channel regulation. Embo Journal 24:705-716.

Kottgen M, Buchholz B, Garcia-Gonzalez MA, Kotsis F, Fu X, Doerken M, Boehlke C, Steffl D, Tauber R, Wegierski T, Nitschke R, Suzuki M, Kramer-Zucker A, Germino GG, Watnick T, Prenen J, Nilius B, Kuehn EW, Walz G. 2008. TRPP2 and TRPV4 form a polymodal sensory channel complex. Journal of Cell Biology 182:437-447.

Le Bouffant R, Jian-Hong W, Futel M, Buisson I, Umbhauer M, Riou JF. 2012. Retinoic acid-dependent control of MAP kinase phosphatase-3 is necessary for early kidney development in Xenopus. Biology of the Cell 104:516-532.

Leclerc C, Webb SE, Miller AL, Moreau M. 2008. An increase in intracellular Ca2+ is involved in pronephric tubule differentiation in the amphibian Xenopus laevis. Dev Biol 321:357-67.

Lienkamp SS, Liu K, Karner CM, Carroll TJ, Ronneberger O, Wallingford JB, Walz G. 2012. Vertebrate kidney tubules elongate using a planar cell polarity-dependent, rosette-based mechanism of convergent extension. Nat Genet 44:1382-7.

Lienkamp SS. 2016. Using Xenopus to study genetic kidney diseases. Semin Cell Dev Biol 51:117-24.

Liu C, Mei M, Li Q, Roboti P, Pang Q, Ying Z, Gao F, Lowe M, Bao S. 2017. Loss of the golgin GM130 causes Golgi disruption, Purkinje neuron loss, and ataxia in mice. Proc Natl Acad Sci U S A 114:346351.

McGrath J, Somlo S, Makova S, Tian X, Brueckner M. 2003. Two populations of node monocilia initiate left-right asymmetry in the mouse. Cell 114:61-73.

Nakamura N, Rabouille C, Watson R, Nilsson T, Hui N, Slusarewicz P, Kreis TE, Warren G. 1995. Characterization of a cis-Golgi matrix protein, GM130. Journal of Cell Biology 131:1715-1726.

Nieuwkoop PD, Faber J. 1975. Normal table of Xenopus laevis (Daudin).: A systematical and chronological survey of the development from the fertilized egg till the end of metamorphosis. North-Holland Pub. Co.

Nishikawa K, Toker A, Johannes FJ, Zhou SY, Cantley LC. 1997. Determination of the specific substrate sequence motifs of protein kinase $C$ isozymes. Journal of Biological Chemistry 272:952-960. 
Paul BM, Vanden Heuvel GB. 2014. Kidney: polycystic kidney disease. Wiley Interdiscip Rev Dev Biol. 3:465-487.

Pennekamp P, Karcher C, Fischer A, Schweickert A, Skryabin B, Horst J, Blum M, Dworniczak B. 2002. The ion channel polycystin-2 is required for left-right axis determination in mice. Current Biology 12:938-943.

Roboti P, Sato K, Lowe M. 2015. The golgin GMAP-210 is required for efficient membrane trafficking in the early secretory pathway. J Cell Sci 128:1595-606.

Sammels E, Devogelaere B, Mekahli D, Bultynck G, Missiaen L, Parys JB, Cai YQ, Somlo S, De Smedt H. 2010. Polycystin-2 Activation by Inositol 1,4,5-Trisphosphate-induced Ca2+ Release Requires Its Direct Association with the Inositol 1,4,5-Trisphosphate Receptor in a Signaling Microdomain. Journal of Biological Chemistry 285:18794-18805.

Saneyoshi T, Kume S, Amasaki Y, Mikoshiba K. 2002. The Wnt/calcium pathway activates NF-AT and promotes ventral cell fate in Xenopus embryos. Nature 417:295-9.

Schweickert A, Weber T, Beyer T, Vick P, Bogusch S, Feistel K, Blum M. 2007. Cilia-driven leftward flow determines laterality in Xenopus. Current Biology 17:60-66.

Seemann J, Jokitalo EJ, Warren G. 2000. The role of the tethering proteins p115 and GM130 in transport through the Golgi apparatus in vivo. Mol Biol Cell 11:635-45.

Shi JL, Zhao Y, Galati D, Winey M, Klymkowsky MW. 2014. Chibby functions in Xenopus ciliary assembly, embryonic development, and the regulation of gene expression. Developmental Biology 395:287-298.

Stoetzel C, Bar S, De Craene JO, Scheidecker S, Etard C, Chicher J, Reck JR, Perrault I, Geoffroy V, Chennen K, Strahle U, Hammann P, Friant S, Dollfus H. 2016. A mutation in VPS15 (PIK3R4) causes a ciliopathy and affects IFT20 release from the cis-Golgi. Nat Commun 7:13586.

Streets AJ, Needham AJ, Gill SK, Ong ACM. 2010. Protein Kinase D-mediated Phosphorylation of Polycystin-2 (TRPP2) Is Essential for Its Effects on Cell Growth and Calcium Channel Activity. Molecular Biology of the Cell 21:3853-3865.

Streets AJ, Wessely O, Peters DJ, Ong AC. 2013. Hyperphosphorylation of polycystin-2 at a critical residue in disease reveals an essential role for polycystin-1-regulated dephosphorylation. Hum Mol Genet 22:1924-39.

Sun Z, Amsterdam A, Pazour GJ, Hopkins N. 2004. A genetic sereen in zebrafish identifies cilia genes as a principal cause of cystic kidney and links the cilium to size control of epithelial tubes. Molecular Biology of the Cell 15:359A-359A.

Tena JJ, Neto A, de la Calle-Mustienes E, Bras-Pereira C, Casares F, Gomez-Skarmeta JL. 2007. Oddskipped genes encode repressors that control kidney development. Dev Biol 301:518-31.

Tetelin S, Jones EA. 2010. Xenopus Wnt11b Is Identified as a Potential Pronephric Inducer. Developmental Dynamics 239:148-159.

Tran U, Zakin L, Schweickert A, Agrawal R, Doger R, Blum M, De Robertis EM, Wessely O. 2010. The RNA-binding protein bicaudal $C$ regulates polycystin 2 in the kidney by antagonizing miR-17 activity. Development 137:1107-16. 
Wong M, Munro S. 2014. The specificity of vesicle traffic to the Golgi is encoded in the golgin coiledcoil proteins. Science 346:601-+.

Wu GQ, Markowitz GS, Li L, D'Agati VD, Factor SM, Geng L, Tibara S, Tuchman J, Cai YQ, Park JH, van Adelsberg J, Hou H, Kucherlapati R, Edelmann W, Somlo S. 2000. Cardiac defects and renal failure in mice with targeted mutations in Pkd2. Nature Genetics 24:75-78.

Zhang B, Tran U, Wessely O. 2011. Expression of Wnt Signaling Components during Xenopus Pronephros Development. Plos One 6.

\section{LEGENDS}

Fig.1 Analysis of protein interacting with TRPP2. A. MS workflow. Late gastrula stage embryos (NF.st12.5) were lysed and subjected to anti-TRPP2 IP, or control IP without primary antibody. In both cases, immunoprecipitated proteins were digested with trypsin on beads. The resulting peptides were fractionated by chromatography before orbitrap MS/MS analysis and protein identification. Proteins co-immunoprecipitated with TRPP2 and absent from control IP were scored for their abundance and selected for further analysis. B. Immunoblotting detection of golgin A2, PrKD1 and dvl2 after TRPP2 IP from NF.st12.5 embryos lysates. C. TRPP2 is co-precipitated in antigolgin A2 and anti-PrKD1 IPs. PrKD1 is neither detected in anti-golgin A2 IPs, nor is golgin A2 in antiPrKD1 IPs, indicating that they do not interact with TRPP2 in the same complex. Inp: NF.st12.5 embryo input lysate; Ctl: control IP lacking primary antibody.

Fig.2 Golga2, prkd1 and $d v / 2$ genes are expressed in both kidney field (KF) and gastrocoel roof plate (GRP). A. Schematic representation of the dissections of GRP and KF explants at neurula stage. B. RTqPCR analysis of gene expression in GRP and KF explants. Accurate dissections of GRP and KF have been validated by checking for $t$ expression in GRP and pax8 expression in KF. Pkd2, golga2, prkd1 and $d v / 2$ are all expressed in GRP and $\mathrm{KF}$, showing that interaction between their encoded proteins can potentially take place in both regions of the embryo. Relative quantities of mRNA are determined using odc mRNA as the endogenous reporter.

Fig.3 Temporal expression of golga2 and prkd1 in developing Xenopus embryos. RT-qPCR analysis reveals a strong maternal expression at NFst.5 that progressively declines during later cleavage stages and gastrulation (NFst9-13), and is stabilized at later stages. Relative quantities of mRNA are determined using odc mRNA as the endogenous reporter.

Fig.4 Spatial expression of golga2 and prkd1 during Xenopus development. A. Gastrula stages. Golga2 and prkd1 are expressed in all tissues. At early gastrula stage, expression is stronger in marginal zone, especially in the dorsal marginal zone (D). At late gastrula stage, golga2 has a higher expression in axial mesoderm (AM). Prkd1 expression is also stronger on the dorsal side of the closing blastopore 
(white arrowhead). B. Tailbud stages. Golga2 and prkd1 are strongly expressed in the developing brain (B) and developing eyes (Ey). They are detected in migrating cranial neural crest (CNC) at early tailbud stage (NFst.24), and later in the developing branchial arches (Br). At late tailbud stages golga2 and prkd1 expressions are also detected in the developing notochord (Nt). Golga2, and to a lesser extent prkd1 transcripts are detected in the pronephric anlage (black arrowhead) at early tailbud stage. Golga2 expression is maintained at mid and late tailbud stages in the proximal region of the pronephric tubule (arrows), while prkd1 transcripts are detected in intermediate and distal segments of the developing pronephric tubule (arrows). Vg : vegetal pole.

Fig.5. Localization of exogenously expressed fluorescent TRPP2 and dv/2 in apical ciliated region of GRP cells. Comparison of GFP- and mcherry-protein expression on optical sections. Dvl2-GFP is generally not expressed in cilia revealed by arl13b-mcherry (A-C). Dvl2 is generally concentrated at the basis of the cilia (arrowheads), but was sometimes co-expressed with arl13b (arrow). In contrast, GFP-TRPP2 is expressed in a vast majority of cilia where it co-localizes with arl13b-mcherry (D-F). Comparison of GFP-TRPP2 and dv12-mcherry localization (G-I) reveals an exclusive distribution in the cilium with dvl2 concentrated at the basis of the cilium and TRPP2 expressed along the cilium. Both dvl2-GFP and dvl2-mcherry are expressed at cell borders where GFP-TRPP2 is not detected $(A, H)$.

Fig.6. Localization of exogenously expressed fluorescent TRPP2 and dvl2 in KF cells. Comparison of GFP-TRPP2 and mcherry-dv12 expression on optical sections. (A-C) Optical section tangential to cell surface. Dvl2-mcherry and GFP-TRPP2 exhibit an exclusive distribution. Both appear as dots possibly corresponding to traffic vesicles. (D-F) Deeper section of the same cells as (A-C). Dvl2-mcherry is associated with cell borders. In some places GFP-TRPP2 is co-localized with dvl2-mcherry at cell borders (arrowheads). 

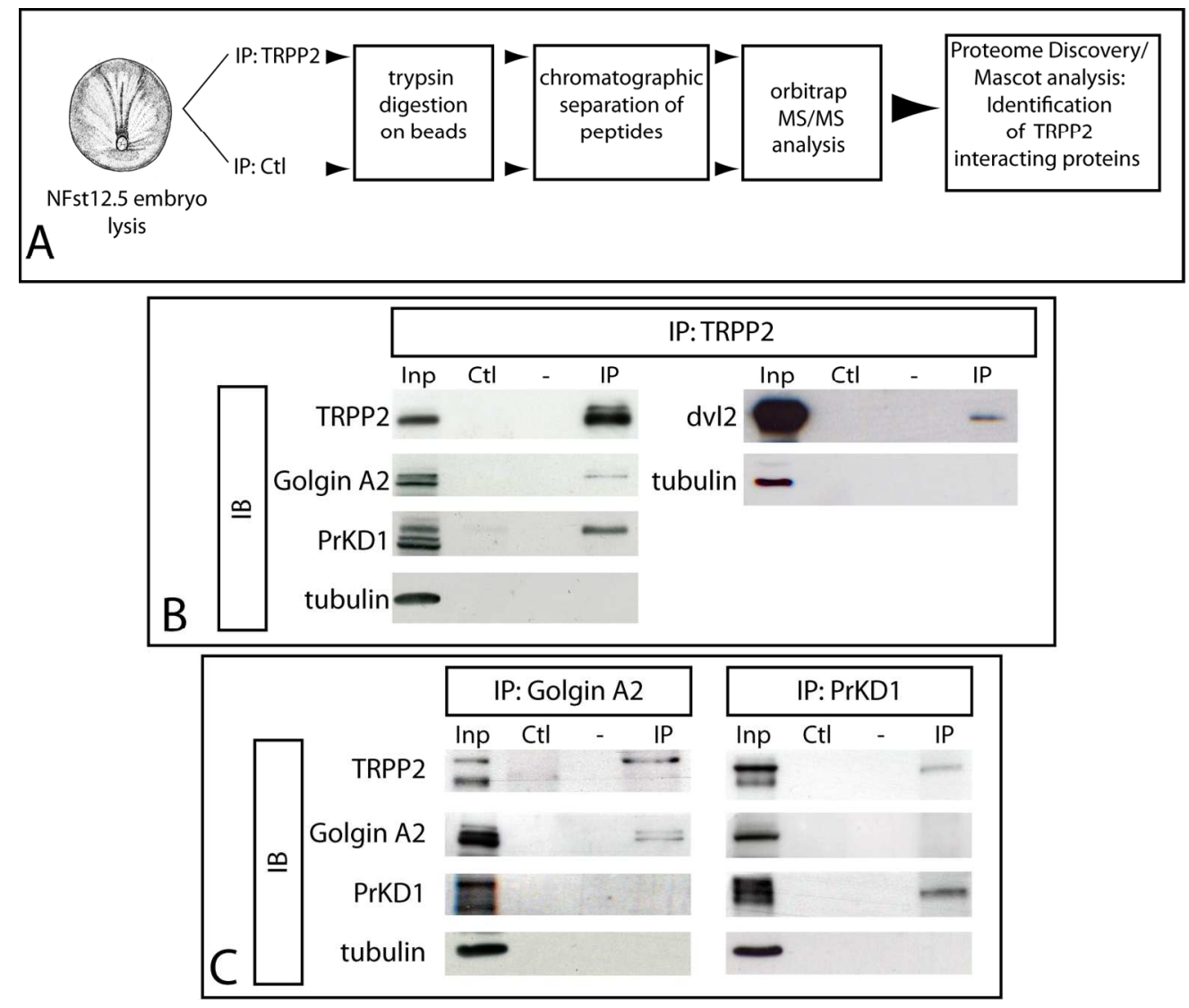

$144 \times 123 \mathrm{~mm}(300 \times 300$ DPI $)$ 
A Gastrocoel Roof Plate (GRP) Kidney Field (KF)

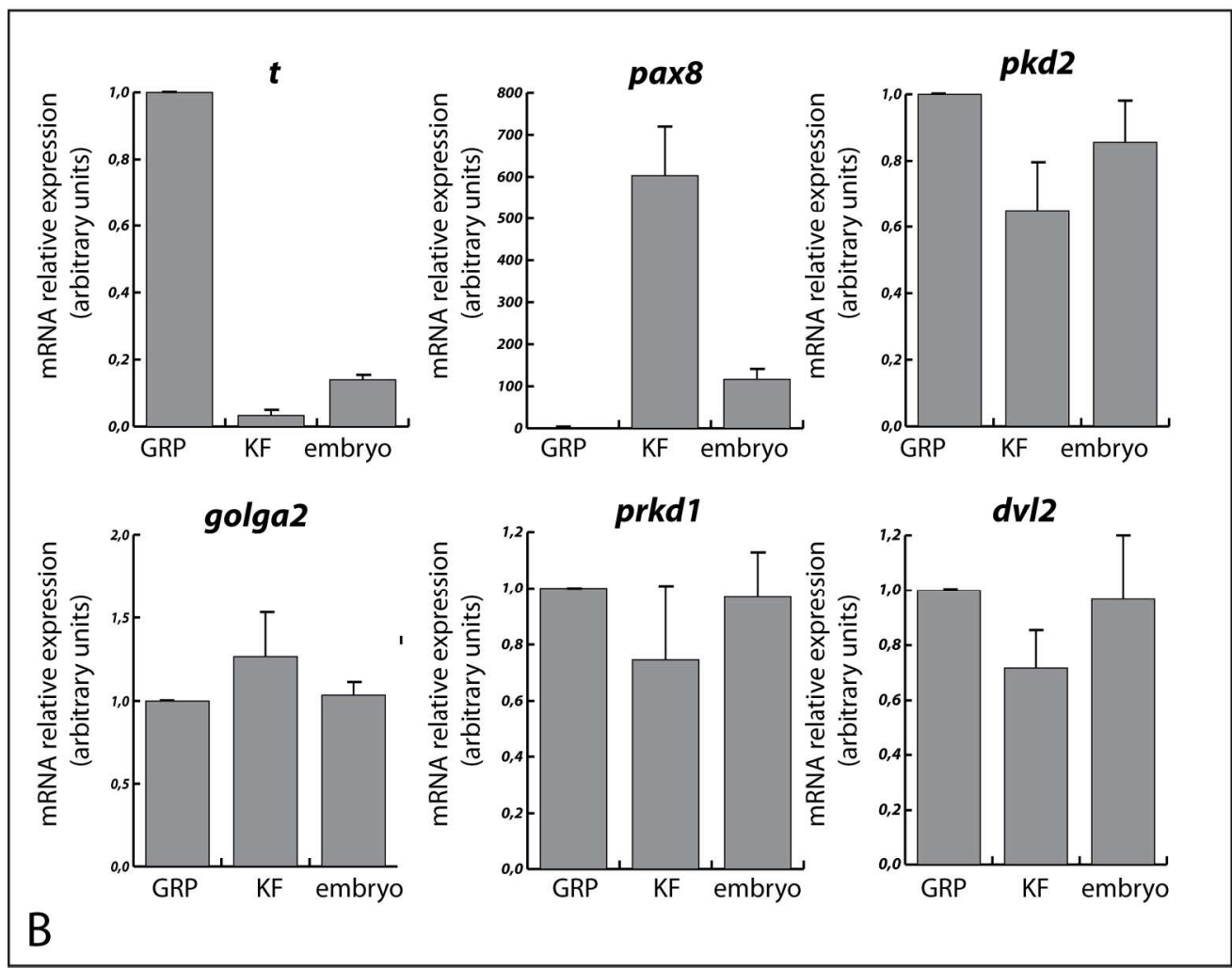

$176 \times 181 \mathrm{~mm}(300 \times 300$ DPI $)$ 

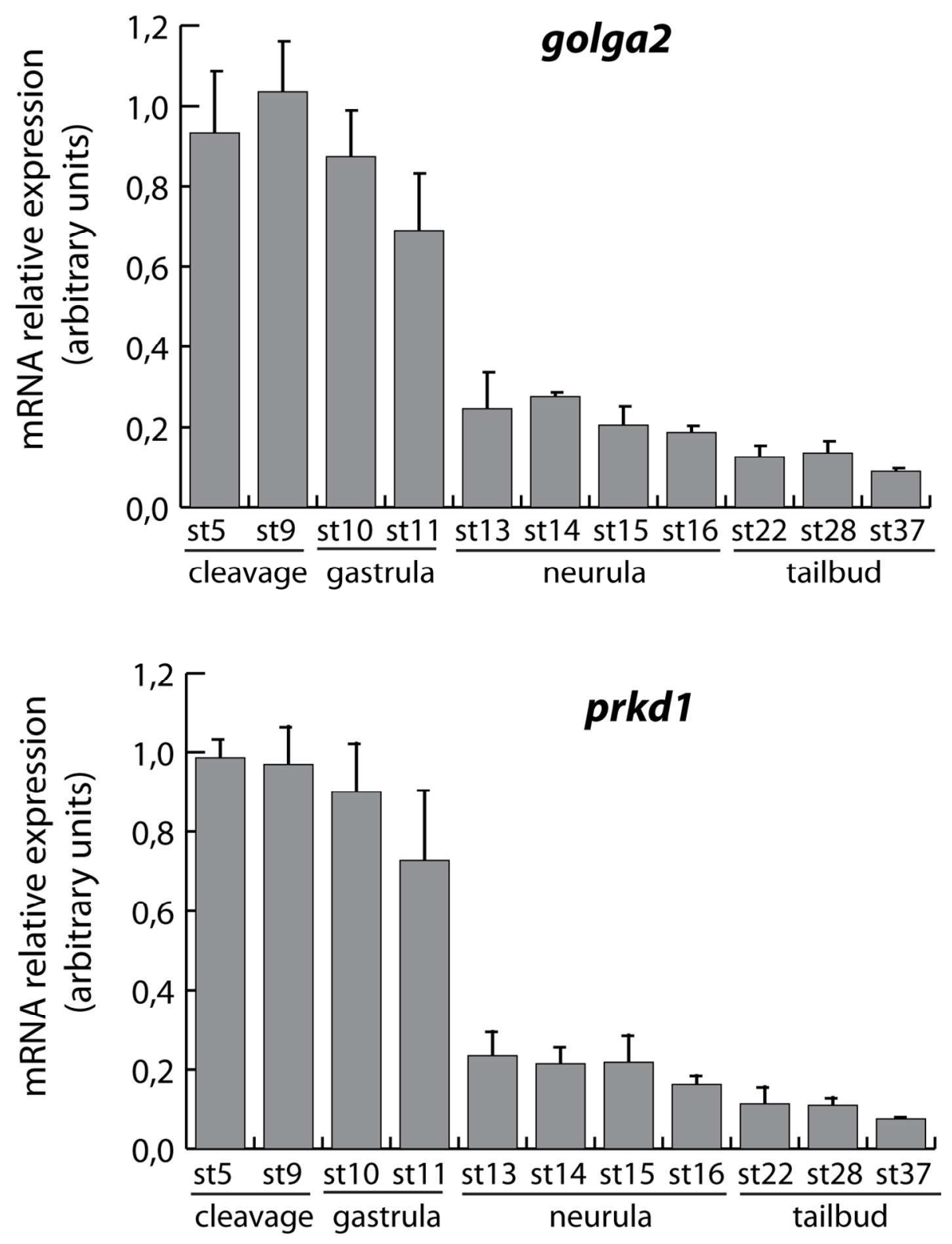

$121 \times 159 \mathrm{~mm}(300 \times 300$ DPI $)$ 


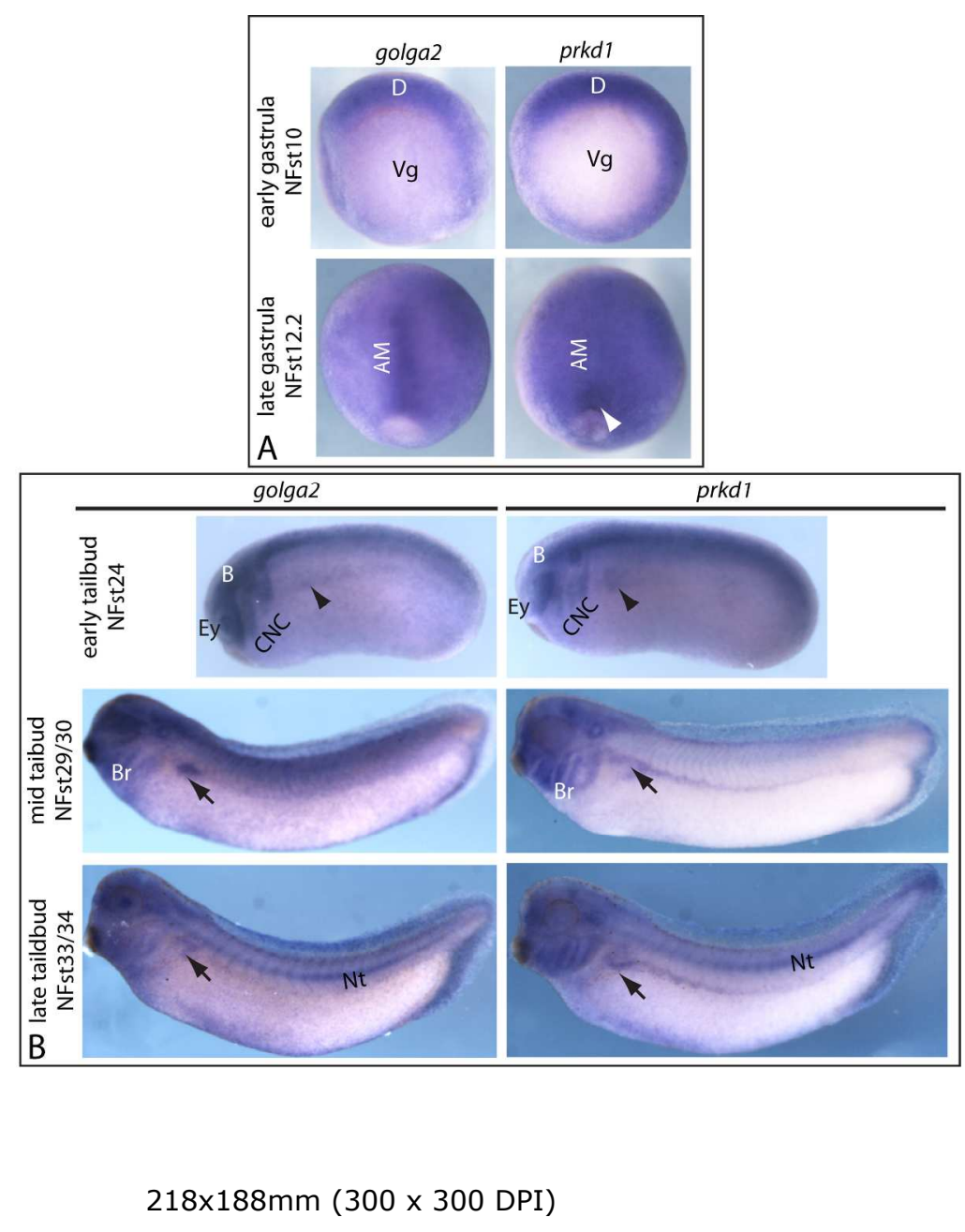









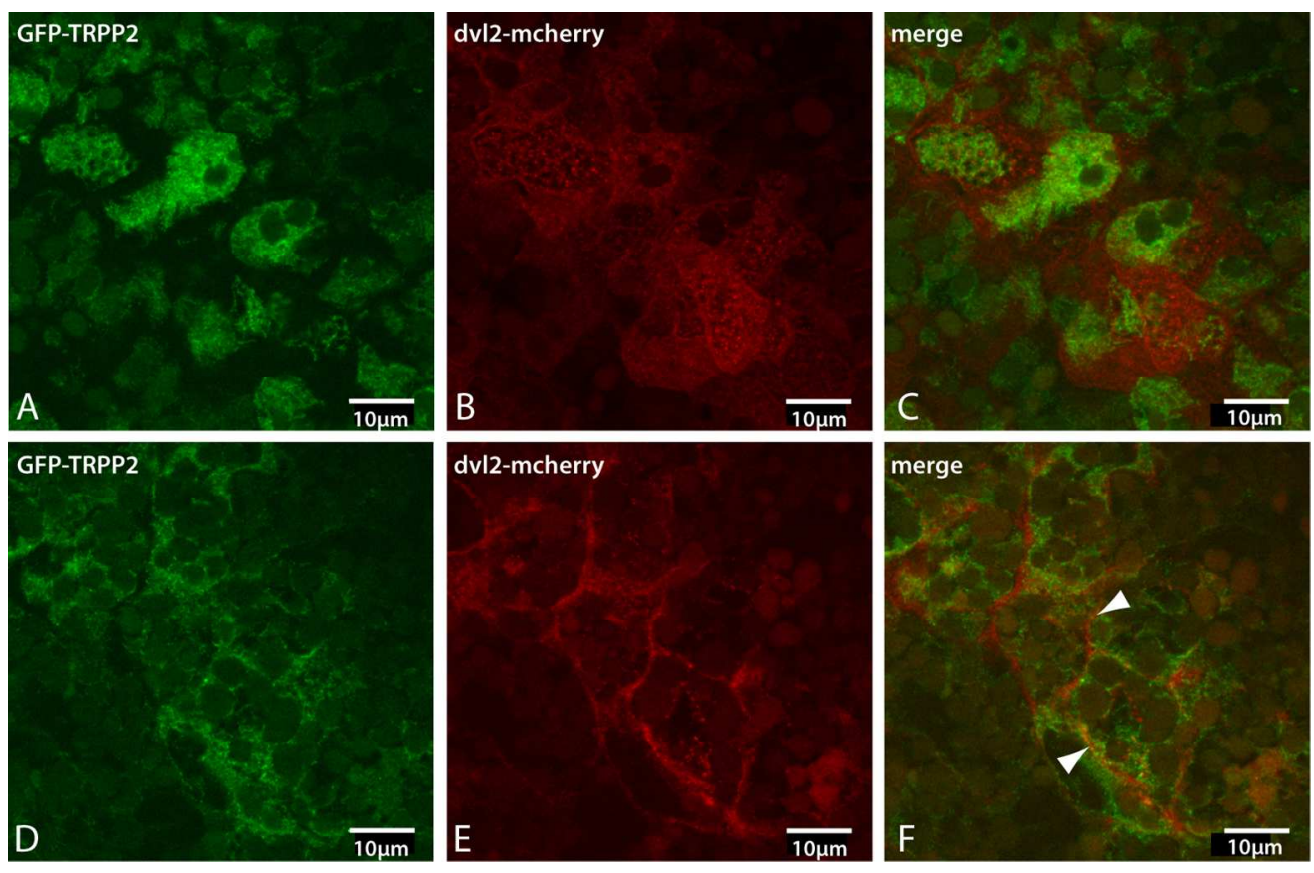

$141 \times 92 \mathrm{~mm}(300 \times 300$ DPI $)$ 


147906887 golgin A2 (golga2) $\quad$ transporter activity (golgi) 572.18

147906757 segment polarity protein

protein binding; signal transducer activity (cell

94.15

surface; cytoplasm; cytoskeleton; membrane; nucleus)

protein binding $\quad 78.00$
glutathione-dependent peroxidase activity $\quad 71.0$ microsomal glutathione S- transferase 3 (mgst3)

62739367 ninein (gsk3ß-interacting protein) (nin)

metal ion binding; protein binding (Centrosome

70.13

basal body)

coat intracellular lipid droplets

67.95 protein, perilipin 2 (plin2)

156119445 transitional endoplasmic

catalytic activity; nucleotide binding; RNA binding

36.75 reticulum ATPase ( $v c p)$

148225959 vesicle (multivesicular body)

synonym LIP5 endosomal EGFR trafficking trafficking 1 (vta1)

54037970 periplakin (ppl)

desmosomal protein

26.84

catalyze formation, reduction, and isomerization of $\quad 26.11$ disulfide bonds in proteins (endoplasmic reticulum) Activated IP3R association/degradation

20.25 (endoplasmic reticulum)

Table 1: TRPP2-interacting proteins potentially involved in trafficking, interaction with Wnt-calcium pathway or cilia function. 


\begin{tabular}{|c|c|c|}
\hline & Forward & Reverse \\
\hline$a c t i n b$ & 5'-TCTATTGTGGGTCGCCCAAG-3' & 5'-TTGTCCCATTCCAACCATGAC-3' \\
\hline odc & 5'-GGGCAAAGGAGCTTAATGTGG-3' & 5'-TGCCAACATGGAAACTCACAC-3' \\
\hline pax8 & 5'- CAGCAATTTCAATATAGGTCACGG-3' & 5'- TCCATTCACAAAAGCCCCAC-3' \\
\hline$t$ & 5'- CACCAAGAATGGAAGACGAATG -3' & 5'- CCCGACATGCTCACCTTCA -3' \\
\hline golga21 & 5'- CAGGTGGAACAGTTGGAGACAA -3' & 5'- TGGTGTGGGCTCAGTGTCTG -3' \\
\hline prkd1 & 5'- AGCTGATCCATTCCCGCAG -3' & 5' - ATGCGAGCAAAGCCGAAAT - 3' \\
\hline$d v / 2$ & 5'- TGAGACTGAGCGTTTCCCATG -3' & 5'- AGAGGCTGAAGAGTGACACCG -3' \\
\hline
\end{tabular}

Table S1: Primers used for RT-QPCR 


\begin{tabular}{|c|c|c|c|c|c|c|c|}
\hline Accession & Description & Encoding gene & Molecular Function & Cellular Component & Biological Process & Score A3 & $\frac{M W[\mathrm{~kb} a]}{11.4}$ \\
\hline 147906887 & 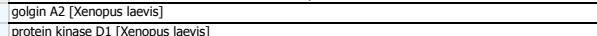 & golga2 & $\begin{array}{l}\text { transporter activity } \\
\text { ing: nucleotide binding: }\end{array}$ & cytoplasm; Golgi; membrane & $\begin{array}{l}\text { metabolic process; transport } \\
\text { requalition of bilogica process }\end{array}$ & $\begin{array}{l}572.18 \\
19.315\end{array}$ & \begin{tabular}{|c|}
111.4 \\
71.4 \\
\end{tabular} \\
\hline 14823642020 & 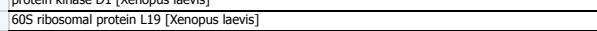 & Prol19 & 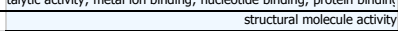 & & metabolic process & $\frac{103.08}{108}+2$. & \\
\hline 147906757 & segment polarity protein dishevelled homolog DVL-2 [Xenopus laevis] & ovis & protein binding; signal transducer activity & Eell surface; cytoplasm; crtoskeleton; membrane; nucleus & ent; metabolic process; regulation of biological proces: & 94.15 & \\
\hline 148223451 & ribosomal protein S19 [Xenopus laevis] & rosti & structural molecule activity & cytoplasm; ribosome & metabolic process & 82.24 & $\frac{16.0}{1.0}$ \\
\hline 18999896962 & $\begin{array}{l}\text { 14-3-3-3 protein zeta a [Xenopus laevis] } \\
\text { uncharacterzed }\end{array}$ & whaz & 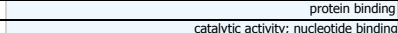 & cytoplasm & & 78.006 & 73.8 \\
\hline 14821734611 & 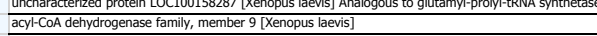 & eceprs & $\begin{array}{l}\text { cataltitic cactivity nuclootide binding } \\
\text { catalytic activity nucleotide binding }\end{array}$ & cytoplasm & 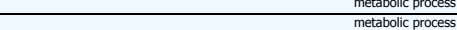 & $\frac{77.76}{76.61}$ & $\frac{738.8}{68.4}$ \\
\hline & & & & & & 74.75 & $\frac{68.4}{45.8}$ \\
\hline & LoC100036792 protetin [Xenopus laeviss inner membrane protetin, mitochondrial & immit & & cytoplasm; membrane; mitcchondrion & & 74,13 & \\
\hline 147902246 & microsomal glutathione s-transferase 3 [Xenopus laevis] & mgst3 & & & & 71.10 & \\
\hline 67 & LoC733210 protein [Xenopous laevis] ninein (GSK3B interacting protetin) & nim & metal ion binding; protetin binding & cytoplasm & cell organization and biogenesis & 70.13 & \\
\hline 5234242618 & 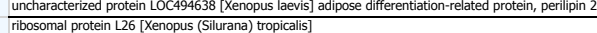 & $2 \frac{\operatorname{lin} 2}{r / 26}$ & $\begin{array}{l}\text { structural molecule activity } \\
\text {. }\end{array}$ & cytoplasm; ribosome & metabolic process & $\frac{67.95}{66.86}$ & $\frac{44.4}{17.2}$ \\
\hline 148227748 & pyrunvate dehydrogenase (lipoamide) alpha 1 [Xenopus laevis] & pothat & 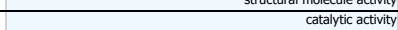 & yycopdasm, inosomine & 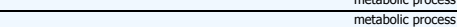 & & \\
\hline & heat shock protetin 90kDa alpha (cytosolic), dass B member 1 [Xenoous laevis] & & nucleotide binding; protetin binding & & spononse to stimulus & & \\
\hline & ribosomal protein L12 [Xenopus laevis] & rppli2 & structural molecule activity & ctoplasm; ribosome & metabolic process & $\frac{62.44}{62.4}$ & $\frac{82.3}{17.8}$ \\
\hline 227920 & chaperonin containing TCP1, subunit 7 [Xenopus laevis] & catr & nucleotide binding; protetin binding & cytoplasm & metabolic process & 61.08 & \\
\hline & 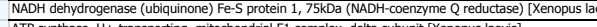 & & catalytic activity; metal ion binding & membrane & metabolic process & 56.29 & 79.5 \\
\hline 00284 & 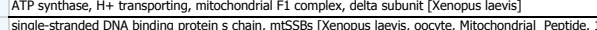 & $\frac{a t 55 d}{125 \text { a } 1}$ & $\begin{array}{c}\text { catalytyic activity; transporter activity } \\
\text { DNA bining }\end{array}$ & $\begin{array}{l}\text { membrane } \\
\text { mitochondrion } \\
\end{array}$ & metabolic process; transport & 53.60 & $\frac{16.9}{14.1}$ \\
\hline 14790292974 & & 125 ald & $\begin{array}{c}\text { DNA bining } \\
\text { structural molecule activity }\end{array}$ & $\begin{array}{l}\text { mitichondrion } \\
\text { cytoplasm; ribosome }\end{array}$ & process & 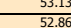 & \\
\hline 227463 & 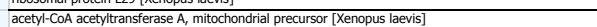 & acath & $\begin{array}{l}\text { stsuctura molecula ectuvity } \\
\text { catalytic activty; metal ion binding }\end{array}$ & $\begin{array}{l}\text { oplasmism; mitochonondrion } \\
\text { ons }\end{array}$ & metabolicicicecess & $\begin{array}{l}\frac{2.20}{5.35} \\
5\end{array}$ & 4.1 \\
\hline 321 & coffilin-1-B [Xenopus laevis] & dit & protein binding & sm; cytoskeleton; membrane; nucleus; ; rganellele lumer & esis; regulation of biological process & 51.86 & \\
\hline 52346106 & 605 ribosomal protein 136 [Xenous (Slivrana) tropicalis] & $1 \mathrm{ppl36}$ & structural molecule activity & cytoplasm; ribosome & development; metabolic process; regulation of biological proceess & 51.01 & \\
\hline 1479 & Chaperonin containing TC1, subunit5 (epsilon) b [XXenopus laevis] & catsb & nucleotide binding; protein binding & cytoplasm & metabolic process & 50.22 & (0.0. \\
\hline 3255412 & & $\frac{r p n 2}{\text { reprs }}$ & $\begin{array}{c}\text { catalytic activity } \\
\text { catallytic activity nucleotid binding }\end{array}$ & $\begin{array}{c}\text { cytoplasm; endoplasmic reticulum; membrane } \\
\text { cottolasmm }\end{array}$ & $\begin{array}{l}\text { metabolic process } \\
\text { mematholicorecses }\end{array}$ & 48.66 & 69.2 .2 \\
\hline 227968 & 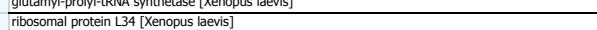 & $\frac{e p r s}{r / 34}$ & 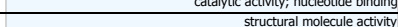 & $\begin{array}{c}\text { cytoplasm } \\
\text { cytoplasm; ribosome }\end{array}$ & $\begin{array}{l}\text { metabonocicrocecss } \\
\text { metabolic process }\end{array}$ & $\frac{47.66}{47.43}$ & 169.3 \\
\hline 23127 & 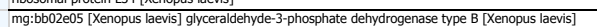 & $g a t$ & 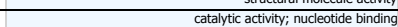 & cyltoplasm & metabolic proctecess & 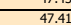 & \\
\hline 23359 & mitochondrial ATP synthase beta subunit [Xenopus laevis] & atpsb & catallytic activity; nucleotide binding; transporter ativity & membrane & metabolic processs; transpost & 45.38 & \\
\hline 62859151 & $\begin{array}{l}\text { ribosomal protein L27 [Xenopus SSlilurana) tropicalis] } \\
\end{array}$ & rpp/27 & structural molecule activity & cytoplasm; ribosome & metabolic process & 44.92 & \\
\hline 104294 & GTP-binding nuclear protein Ran [Xenopus laevis] & ran & nucleotide binding & & regulation of biological process & 44.08 & \\
\hline 39525 & 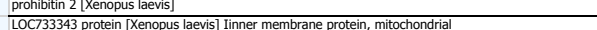 & $\frac{p h b 2}{i m m t}$ & & $\begin{array}{l}\text { membrare } \\
\text { chtoplasm; membrane; intchlondion }\end{array}$ & & 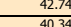 & \\
\hline 99525 & IIInner membrane proteln, mitochondral & $\frac{i m m t}{\operatorname{col} 18}$ & & ctopolasm; membrane; mitochondrion & & 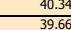 & \\
\hline & elongation factort 1-alpha (454 AA) [Xenopus laevis] & eefiato & catalytic activity; nucleotide binding & & & 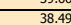 & \\
\hline & nation factor 1-beta [Xenopus laevis] & eefibz & RNA binding & cytoplasm & metabolic process & 38.29 & \\
\hline$m_{2}$ & chaperonin subunit 8 theta [Xenopus laevis] & cats & nucleotide binding; protein binding & cytoplasm & metabolic process & 37.82 & \\
\hline & transtitional endoplassnic reticulum ATPase [Xenopus laevis] & $v e p$ & tivity; nucleotide binding; RNA binding & ( & metabolic process; reproduction; response to stimulus & 36.75 & \\
\hline & 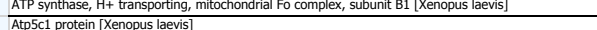 & $\begin{array}{l}a t p 551 \\
a t a c t\end{array}$ & $\begin{array}{l}\text { trasspoter activity } \\
\text { cataly }\end{array}$ & $\begin{array}{c}\text { ctopolasm; membrane; mitochendrion } \\
\text { membrane }\end{array}$ & $\begin{array}{l}\text { metabibil crocecss transport } \\
\text { metabolic process transport }\end{array}$ & 年, & \\
\hline & 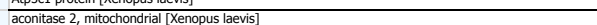 & 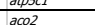 & 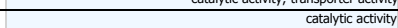 & & metabolic process & $\begin{array}{l}3.45 \\
\end{array}$ & \\
\hline & 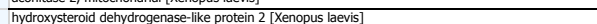 & 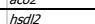 & catalticic adivivity nucleostide binding & cytolasm & $\begin{array}{lll}\text { meatabolic process } \\
\text { metas }\end{array}$ & & \\
\hline & 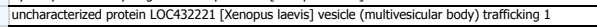 & vtat & 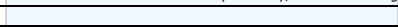 & & & 31.31 & \\
\hline & NADH dehyrogogenase (ubiquinone) 1 alpha subcomplex, 9 , 39kDa [Xenopus laevis] & ndufag & catalytici activity; nucleotide binding & & metabolic process & 30.61 & \\
\hline 702 & ribosomal protein S10 [Xenopus laevis] & rpstio & 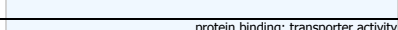 & gatoplasm. nycleus & & & \\
\hline & 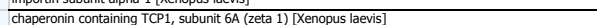 & 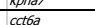 & 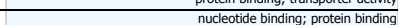 & 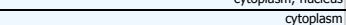 & tirassopotit & 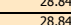 & \\
\hline & hevis] & $\cos 1$ & catallytic activity; metal ion binding; nucleotide binding & & meta & 67 & \\
\hline & glutathione s-transferase [Xenopus & hopds & cataltic activity protetein binding & & & $7.58 \mathrm{~S}$ & \\
\hline 148 & sorting and assembly machinery & 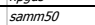 & & cytoplasm; membrane; mitcochondrion & & $26.92 \mathrm{C}$ & \\
\hline & LoC4950553 prc & pol & & desmosome & & .84 & \\
\hline & 16363 & & 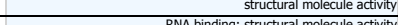 & cytoplasm; ribobsome & ess & 4. 48 & \\
\hline 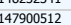 & |levis] & 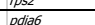 & 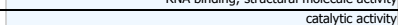 & & 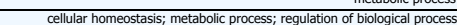 & 6. & \\
\hline & member 10 & $s c_{c \mid 25 a}$ & & & 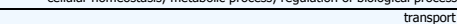 & & \\
\hline & CP1, subunit 2 (beta) Ixen, & cat & leotide binding; prt & cytoplasm & bolic process & 23.48 & \\
\hline & in Chinese hamster cells 6 [Xenopus laevis] & 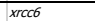 & talytic activity; DNA binding; pr & nucleus & metabolic process; response to stimulus & 2.98 & \\
\hline & is laevis transformer 2 alpha homolog & tra 22 & nucleotide binding & & (- & .66 & \\
\hline 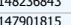 & 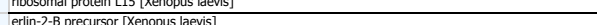 & tolls & structural molecule activ & 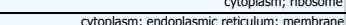 & metaboil process & 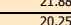 & 36.8 \\
\hline
\end{tabular}




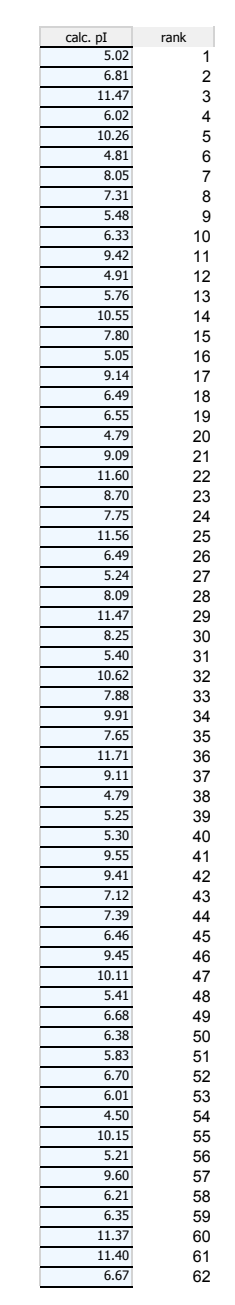

32

33

34

35

37

3.

39

41
42

43

44

45

46

47 
Table S2: proteins specifically detected in TRPP2 immunoprecipitates and absent from control immunoprecipitates. Proteins are ranked according to their mascot score (scoreA3). For each accession number, protein sequence was obtained from NCBI database, and blasted on Xenbase $X$. laevis proteins. In some cases where NCBI description was incomplete, further protein identification obtained from Xenbase is added $\mathrm{n}$ the column "description". Gene names from Xenbase gene models are given in a separate column. Details about discriminating peptides are accessible by selection of menu on left. 